\title{
La couleur des cheveux est sans effet sur les résultats des dosages de cocaïne, benzoylec- gonine, morphine, 6-monoacétylmorphine, codéine et 11-nor-9-carboxy- $\Delta 9$-THC. Étude dans le cadre de la médecine du travail
}

\section{Absence of hair color effects in hair analysis results for cocaine, benzoylecgonine, morphine, 6-monoacetylmorphine, codeine and 11-nor-9-carboxy- $\triangle 9$-THC in large workplace populations}

Virginia HILL*, Michaël SCHAFFER, Thomas CAIRNS

Psychemedics Corporation, Culver City, California - USA

*Corresponding Author: Virginia HILL, Psychemedics Corporation, 5832 Uplander Way, Culver City - CA 90230 - USA Tel : 0013102167776 - E-mail : virginiah@psychemedics.com

(Reçu le 7 novembre 2005 ; accepté le 17 décembre 2005)

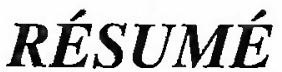

Deux approches ont été utilisées pour déterminer les effets de la couleur des cheveux sur les concentrations des stupéfiants dans les cheveux, lors de surveillance de conduites addictives en entreprise. Une approche a étudié la distribution des concentrations en drogues dans les cheveux lors d'essais menés en entreprise. Ces distributions ont été comparées à des exemples hypothétiques prédisant l'absence ou la présence d'influence de la couleur des cheveux. Aucune influence de la couleur des cheveux dans la distribution des résultats (de la LOD aux valeurs les plus élevées) n'a été mise en évidence. L'autre approche a séparé les résultats des cheveux noirs et bruns/blonds en déciles et a comparé les

\begin{abstract}
SUMMARY
Two approaches to analyzing workplace drug testing results for effects of hair color on concentrations of drugs of abuse in hair were applied. One approach determined the distributions of hair drug concentrations over the ranges obtained in workplace testing. The distributions were compared to hypothetical examples predicting absence or presence of a color bias (twofold or fivefold). No influence of hair color in the distribution of results from $L O D$ to the highest values was evident. The other approach divided black hair and brown/blonde hair results into deciles and compared the means of comparable deciles of the two populations. Decile means results, when compared to models of hypothetical
\end{abstract}


moyennes des déciles des deux populations. Les résultats de moyennes des déciles, comparés à des modèles de biais hypothétiques n'ont pas montré d'influence de la couleur pour la cocaïne, la benzoylecgonine, la morphine, la 6MAM, la codéine et le $\Delta 9$-carboxy-THC. Les résultats sont particulièrement significatifs car issus d'une très grande population de sujets, caractéristique non accessible à la plupart des laboratoires. Les résultats de l'analyse des cheveux dans plusieurs laboratoires, suggérant l'existence d'une influence de la couleur des cheveux, sont vraisemblablement hautement dépendants des procédures du laboratoire, et spécialement celles utilisés pour éliminer les contaminations et la sueur, à l'origine de contaminations dont les effets sur les résultats des analyses est très influencé par la porosité des cheveux et les pratiques hygiéniques. Les résultats présentés ont été obtenus avec des procédures de lavages énergiques suivis de digestion enzymatique des cheveux.

\section{Introduction}

A number of publications have discussed the possible existence of a melanin or color bias in hair analysis for drugs of abuse, with evidence generally deriving from results of in vitro and rodent experiments, and small human experiments. The in vitro approach has included experiments of drug binding to isolated melanin (1), to melanocyte membranes $(2)$, to synthetic melanin $(3,4)$, or to hair strands cut short or long (1,5-9). Results of in vitro binding of drugs to melanin, however, cannot be extended to in vivo environments. While some information may be obtained regarding binding characteristics in a simple environment of drug, melanin and some chosen buffer system, what cannot be predicted from such studies is the nature and extent of binding in the entirely different and complex chemical environment of a growing hair follicle fed by the circulating blood via the microcapillaries (1). As limited as isolated melanin and melanocyte binding studies may be in predicting drug deposition in the actual growing hair fiber, more misleading are those studies that soak intact hair in drugs in vitro as a means of studying melanin binding, because these soaking studies fail to take into account diffusion as the controlling step. That is, melanin in hair resides in granules within the cortex and medulla (10), and thus penetration of drug to the melanin is diffusion controlled. Not only has the controlling factor of diffusion not been recognized, but, in addition, variabilities in conditions that affect drug penetration, in combination with inadequate washing methods, have led to erroneous conclusions. Specifically, if a hair is porous, large amounts of drug enter the hair during soaking, and also are removed from the hair by aqueous washing, provided the washing is adequately prolonged to allow for reverse diffusion of the drug out of the hair into the wash solution $(11,12)$. bias, showed no evidence of color bias for cocaine, benzoylecgonine, morphine, 6-MAM, codeine or A-9-carboxy-THC. The results are particularly meaningful as they represent very large populations of subjects, a feature unavailable to most laboratories. Hair analysis results suggesting existence of hair color bias in some laboratories are likely highly dependent on laboratory procedures, especially those utilized to remove contamination and sweat, two sources of drug whose effects on hair analysis are greatly influenced by hair porosity and hygienic practices. Results presented were obtained with aggressive washing procedures followed by enzymatic digestion of the hair.

In vivo experiments with rats, mice, and guinea pigs injected with drugs have been reported to show differences in uptake related to melanin content $(7,13-22)$. Assuming that adequate wash procedures were utilized to remove urinary, fecal, cage-mate, bedding, preening (which includes licking by an animal of its own fur), and any other sources of contamination, the usefulness of such studies does not extend to predicting drug binding behaviors in human hair. Animal hair is structurally very different from human hair (23) and rodent and human metabolism differ in many ways. For example, injection of rats with codeine resulted in presence of morphine in the hair (24), while the authors have shown that morphine in hair does not coincide with codeine use in humans (25). While animal models can be useful, they remain only models, and it is important to refrain from overstating implications and extrapolations of results to humans.

In vivo experiments with injected drugs in humans have been claimed to show color bias in hair drug content (26 - 30). However, these experiments have necessarily relied on small numbers of subjects, substituted a different compound safe for injection, or have failed to adequately wash samples or apply efficient extraction methods. In addition, a statistical review of some of these human studies by Mieczkowski and Newel concluded that a "systematic bias" was actually not demonstrated in these studies. Instead, Miezckowski and Newel suggested that individual biological variability may be a larger contributor than hair color to variations in dose response of hair to drug intake (31).

In contrast to these approaches to evaluating effects of hair color in hair analysis for drugs, there have been efforts by laboratories with access to very large numbers of human head hair samples to obtain a broader view by evaluating, retrospectively, whether a color effect in drug-positive results can be demonstrated in 
actual workplace testing. This has been done by two different laboratories, using somewhat different methods. Kelly et al. compared hair analysis positive rates to urinalysis positive rates for cocaine, amphetamines, and cannabinoids in groups categorized by both hair color and ethnic/racial group (32). For hair, results of 500 subjects per drug were evaluated; for urinalysis, approximately 400 urine results, from two different groups, were examined. They concluded that the observed outcome patterns of both urine and hair results were similar and were "largely consistent with differences in drug preferences among the various groups," and they failed to find evidence of "a hair color bias or selective binding of drugs to hair of a particular color (32)."

Data from another laboratory, Psychemedics Corporation, have been analyzed in a similar manner by Mieczkowski and Newel $(33,34)$ with results similar to those of Kelly et al. One such study was done with 1161 human subjects with whom the relative frequency of cocaine use was investigated in 315 African American ("black") and 846 Caucasian ("white") arrestees by use of self reports, urinalysis and hair analysis (34). The proportional relationships among the measures were consistent for each group. Thus, for example, the black group had a greater percentage of positives by both urine and hair, consistent with a higher rate of self-reported use. The authors concluded that, relative to self report, the data did not suggest a bias based on racial group in either urine or hair assays.

Hoffman also compared positive rates for urine and hair results of candidates tested for employment with a large metropolitan police department (35). Results of marijuana and cocaine testing of the candidates, selfreported as "white" or "black," showed no evidence of one group being more adversely affected by hair testing as compared with urine testing (35).

Consistent with the commonly held theory that neutral and acidic compounds are not expected to show a melanin-based bias because binding to melanin correlates positively with basicity, Mieczkowski found no difference in 11-nor-9-Carboxy- $\Delta$ 9-tetrahydrocannabinol (carboxy-THC) concentrations in 1038 black and 2376 brown hair samples from workplace testing (36). Using a slightly different approach, Mieczkowski et al. calculated the relative risk among police officers for a positive outcome for cocaine by urine and hair, employing a data set of 40,318 urine tests and 6,366 hair tests (37). An odds ratio was calculated as the ratio of the $(+)$ odds for white subjects divided by the $(+)$ odds for black subjects for the urine tests and for the hair tests. The officers self reported their racial classifications, and the hair analyses were performed by
Psychemedics Laboratory. The results indicated that, although hair tests detect cocaine use more frequently than urinalysis, there was not a difference in outcome likelihood that was directly related to the type of assay.

Mieczkowski also performed a statistical analysis of morphine concentrations in workplace samples identified as black/curly vs. other hair types (38). Although the sample size for some hair colors (especially blonde and grey) were too small for definitive results, analysis of the samples revealed no significant effect of hair color or curvature on morphine concentrations.

Although these evaluations of actual drug concentrations in large groups of samples have the advantage of looking at the larger picture, countering the distortions and limitations of the in vitro, animal and small human studies, they have been criticized as not sufficiently addressing a possible effect of bias at low concentrations (39-41), where potentially one hair type could retain more drug for a given dose and thus fall just above the cutoff while another might retain less and produce a negative result just below the cutoff (assuming both subjects have ingested the same amount of drug). In the present paper, we analyze large sets of data in order to identify such an effect if it exists. The results of morphine, 6-MAM, codeine, cocaine, benzoylecgonine, and marijuana in hair from very large populations of subjects are evaluated.

\section{Methods}

\section{Sample screening and washing}

All of the hair drug content results presented were obtained in the course of workplace drug testing for the SAMHSA-5 drugs of abuse at Psychemedics Corporation's laboratory. Samples were weighed, digested and assayed using the company's FDA-cleared patented radioimmunoassay of hair digests $(42,43)$. The procedure for samples positive for cocaine or opiates in the screening assays was to weigh another 12 $\mathrm{mg}$ sample and subject it to the washing procedure previously described (11). In brief, the washing consists first of a 15 -minute isopropanol wash at $37^{\circ} \mathrm{C}$ with brisk shaking, after which the isopropanol is removed and discarded. This is followed by three 30-minute and two sixty-minute washes at $37^{\circ} \mathrm{C}$ with vigorous shaking. After each timed interval the washes are discarded, except for the last, which is saved for analysis to determine the wash criterion (11).

Samples positive in the marijuana screening assay are also re-weighed and washed, utilizing a shorter wash procedure. Because carboxy-THC is not present in the environment but can only be present in hair from meta- 
bolic processes, three half-hour washes are sufficient to clean the hair sample prior to digestion.

\section{Confirmation analyses}

For cocaine and opiates confirmation analyses, washed hair was enzymatically digested as previously described (44) for six hours-at $\mathrm{pH} 5.5$ for cocaine and metabolites and $\mathrm{pH} 6.65$ for opiates. MS analyses of cocaine and opiates were performed by liquid chromatographic-tandem mass spectrometric (LC-MS-MS) analysis. Analysis was performed on a triple quadrupole API 2000 Perkin Elmer Sciex (Thornhill, On, Canada) MS equipped with an atomospheric pressure ionization source via an ionspray interface. For LC, a binary pump with an autosampler ISS 200 Perkin Elmer was used. The mobile phase was a mixture of water and acetonitrile containing $0.1 \% \mathrm{HCOOH}$. The proportion of water/acetonitrile was 80:20. Ionization of analytes was obtained in positive mode. Fragmentation was obtained using nitrogen as the collision gas. The MS was operating in the multiple reaction monitoring mode (MRM).

Samples for cocaine analysis were extracted using Isolute SPE columns. The high performance (HPLC) column was a Keystone Scientific BETASIL C8. The target ions for cocaine and its internal standard cocaine-d3 were $\mathrm{m} / \mathrm{z} 182$ and $\mathrm{m} / \mathrm{z} 185$, respectively. Ions $\mathrm{m} / \mathrm{z} 210$ and $\mathrm{m} / \mathrm{z} 213$ were monitored for derivatized benzolyecgonine and its $\mathrm{d} 3$-internal standard. Ions $\mathrm{m} / \mathrm{z}$ 196 and $\mathrm{m} / \mathrm{z} 199$ were monitored for cocaethylene and its $\mathrm{d} 3$-internal standard. Ions $\mathrm{m} / \mathrm{z} 168$ and $\mathrm{m} / \mathrm{z} 171$ were monitored for norcocaine and its $\mathrm{d} 3$-internal standard. The instrument was operating using unit resolution on both Q1 and Q3.

For analysis of opiates by MS, samples were extracted using Cerex SPE columns. The high performance (HPLC) column was a Keystone Scientific BETASIL C8. The target ions for codeine and its internal standard codeine-d 3 were $\mathrm{m} / \mathrm{z} 165$ and $\mathrm{m} / \mathrm{z} 165$, respectively. Ions $\mathrm{m} / \mathrm{z} 165$ was also used to monitor for morphine, 6 acetylmorphine, and its $\mathrm{d} 3$-internal standard. The run time was approximately 10 minutes. The instrument was operating using unit resolution on both Q1 and Q3.

\section{Sample selection}

All of the hair analysis results presented were from workplace samples that screened positive by RIA. The reactivity of the antibody in the opiate RIA screening assay is less for codeine than for morphine, and thus some of the codeine results are those that were detected by concurrent presence of morphine. The screening assays for cocaine and marijuana detect metabolites or related compounds in addition to the parent drug (43). For the analyses presented in this paper, only the results for black hair as one group, and the combined data for brown and blond hair as the other, were utilized. When weighing the hair for screening, the technicians also indicate (by bar-code wand) the perceived color of the hair. While this method of categorizing hair colors was visual, any subjectivity effects were likely mitigated by the large number of samples, such that if a bias is not detected in samples seen to be black by uninterested handlers, then this certainly suggests lack of any significant color bias. Only head hair samples were included, and samples that were recorded as cosmetically treated (as verified by macroscopic observation) by the laboratory were excluded.

\section{Method of data evaluation}

To evaluate these data sets of drug-positive hair results, we examined the distributions of drug concentrations in hair over the entire set of drug-containing hair results, including samples below the cutoff (starting at LOD). The methods of evaluation will be illustrated here with some hypothetical cases, to demonstrate the differences between populations that arithmetic demands if a hair color bias exists. As a first example, assume a set includes 100 people with black hair (Group A) and 100 people with brown/blond hair (group B), all consuming from $1-10$ units of a certain drug per unit time. In this case, 10 subjects in each group take 1 unit of drug, 10 people take 2 units, and so on to 10 units (Table I). If the amount deposited in the hair per unit dose for Group A is twice that for Group B, then the amounts of drug in the hair of the two groups might look similar to those in the columns Hair Drug Content (Table I). For example, the hair drug content resulting from 1 unit of drug dose in Group A is 2 units, while Group B subjects with the same dose have a hair drug content of only 1 unit.

Table I : Hypothetical Hair Drug Content for Two Populations With Uniform Distributions of Doses over the Dose Range and One Group Retaining Twice the Drug Per Unit Dose.

\begin{tabular}{|c|c|c|c|c|c|}
\hline & & \multicolumn{2}{|c|}{ Group A (Black Hair) } & \multicolumn{2}{c|}{ Group B (Brown Hair) } \\
\cline { 3 - 6 } Drug & $\begin{array}{c}\text { n in } \\
\text { each } \\
\text { group }\end{array}$ & $\begin{array}{c}\text { Hair } \\
\text { Drug }\end{array}$ & $\begin{array}{c}\text { Content } \\
\text { Go of }\end{array}$ & $\begin{array}{c}\text { Hair } \\
\text { Drug } \\
\text { Gontent }\end{array}$ & $\begin{array}{c}\text { \% of } \\
\text { Group }\end{array}$ \\
\hline 1 & 10 & 2 & 10 & 1 & 10 \\
\hline 2 & 10 & 4 & 10 & 2 & 10 \\
\hline 3 & 10 & 6 & 10 & 3 & 10 \\
\hline 4 & 10 & 8 & 10 & 4 & 10 \\
\hline 5 & 10 & 10 & 10 & 6 & 10 \\
\hline 6 & 10 & 12 & 10 & 6 & 10 \\
\hline 7 & 10 & 14 & 10 & 7 & 10 \\
\hline 8 & 10 & 16 & 10 & 8 & 10 \\
\hline 9 & 10 & 18 & 10 & 9 & 10 \\
\hline 10 & 10 & 20 & 10 & 10 & 10 \\
\hline
\end{tabular}


The retention of twice the amount of drug per unit dose in Group A relative to Group B is revealed in the distribution of the hair drug content results. For example, subjects with Hair Drug Content of 2 or less include $10 \%$ (10 subjects) of Group A, but $20 \%$ of Group B: 10 with hair drug content of 1 and 10 with hair drug content of 2 (or $20 \%$ of the population). Continuing to group the population by Hair Drug Content, those subjects with 3-4 units hair drug content will comprise $10 \%$ of Group A, and $20 \%$ of Group B. Above 10 Hair Drug Content Units, Group B will have $0 \%$ of subjects with the higher concentrations, while Group A will continue to have increasing Hair Drug Concentrations extending to 20 units. These distributions are shown in Figure 1.

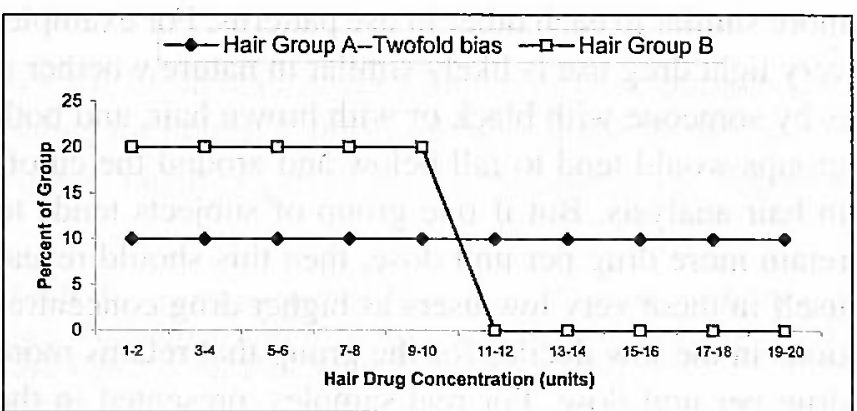

Figure 1 : Distribution of Hair Drug Concentrations for Two Hypothetical Populations with Uniform Distribution of Doses over the Dose Range and One Group Retaining Twice the Drug Per Unit Dose.

Figure 1 shows this relationship graphically. When percents of the group with designated Hair Drug Content values are plotted against increasing Hair Drug Content, Group B (brown/blonde) has higher percentages to the left of the chart, while Group A (black) has percentages lower than Group B on the left of the chart and higher than Group $A$ to the right.

However, the first example is not representative of the real world in that it assumes as many people taking low doses of the drug as high doses. That this is not typical is seen in workplace testing of hair samples, where, for example, $26.3 \%$ of positive cocaine results were in the range of $5-10 \mathrm{ng} / 10 \mathrm{mg}$ hair, $40 \%$ in the range of 10 50 , and percentages of the positive population continued to decrease as concentrations increased (45). In the next example (Table $\mathrm{I}$ ), therefore, we assume that more people take low doses, in the following manner: 19 people take 1 unit, 17 take 2 units, 15 take 3 units, etc. The same twofold bias for Group A relative to Group B is assumed. Table II shows 19 Group B subjects with hair drug content of 1 , and 17 with hair drug content of 2-i.e., 38 subjects total ( $38 \%$ of the population) in the range of hair drug content 1-2. Group A has only 19 subjects, or $19 \%$ of the population, in that range. (Again, all of the Group B subjects have hair drug content of 10 or less, while Group A has a distribution of hair drug content extending to 20 units.) Figure 2 charts these relationships, with $100 \%$ of Group B subjects falling on the left half of the chart, while half of Group A has concentrations in hair out to 20 units, as this population would have if it is assumed to have a twofold bias.

Table II : Hypothetical Hair Drug Content and Distribution for Two Populations With Non-Uniform Distributions of Doses over the Dose Range and One Group Retaining Twice the Drug Per Unit Dose.

\begin{tabular}{|c|c|c|c|c|c|}
\hline \multirow[b]{2}{*}{$\begin{array}{l}\text { Drug } \\
\text { Dose }\end{array}$} & \multirow[b]{2}{*}{$\begin{array}{l}n \text { in } \\
\text { each } \\
\text { group }\end{array}$} & \multicolumn{2}{|c|}{ Group A (Black Hair) } & \multicolumn{2}{|c|}{ Group B (Brown Hair) } \\
\hline & & $\begin{array}{l}\text { Hair } \\
\text { Drug } \\
\text { Content }\end{array}$ & $\begin{array}{l}\% \text { of } \\
\text { Group }\end{array}$ & $\begin{array}{l}\text { Hair } \\
\text { Drug } \\
\text { Content }\end{array}$ & $\begin{array}{l}\% \text { of } \\
\text { Group }\end{array}$ \\
\hline 1 & 19 & 2 & 19 & 1 & 19 \\
\hline 2 & 17 & 4 & 17 & 2 & 17 \\
\hline 3 & 15 & 6 & 15 & 3 & 15 \\
\hline 4 & 13 & 8 & 13 & 4 & 13 \\
\hline 5 & 11 & 10 & 11 & 5 & 11 \\
\hline 6 & 9 & 12 & 9 & 6 & 9 \\
\hline 7 & 7 & 14 & 7 & 7 & 7 \\
\hline 8 & 5 & 16 & 5 & 8 & 5 \\
\hline 9 & 3 & 18 & 3 & 9 & 3 \\
\hline 10 & 1 & 20 & 1 & 10 & 1 \\
\hline
\end{tabular}

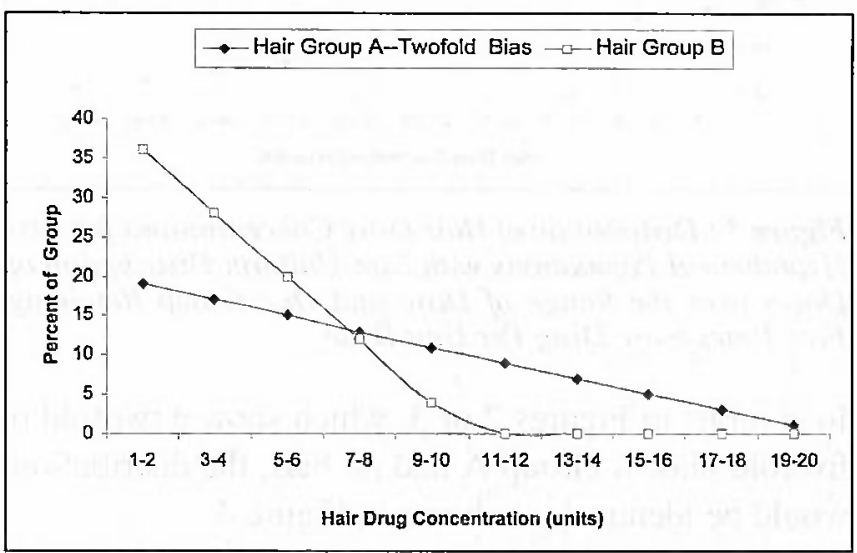

Figure 2 : Distribution of Hair Drug Concentrations for Two Hypothetical Populations with Non-Uniform Distribution of Doses over the Range of Dose and One Group Retaining Twice the Drug Per Unit Dose.

Using the same dosage characteristics as in Table II, a fivefold instead of twofold bias for Group A would produce the concentrations in hair shown in Table III and the distributions shown in Figure 3. In this case, $75 \%$ of Group B samples fall in the range of 1 - 5 units of hair drug content and $25 \%$ in the $6-10$ range, while Group A hair drug content extends to 50 units. The distribution, shown in Figure 3, shows how readily apparent such an extreme bias appears graphically, as a full $75 \%$ of Group B samples has less than 15 units drug concentration and thus falls to the far left of the graph, while Group A has subjects with higher concentrations all the way to 50 units. 
Table III : Hypothetical Hair Drug Content for Two Populations With Non-Uniform Distributions of Doses over the Dose Range and One Group Retaining Five Times Greater Drug Per Unit Dose.

\begin{tabular}{|c|c|c|c|c|c|}
\hline \multirow[b]{2}{*}{$\begin{array}{l}\text { Drug } \\
\text { Dose }\end{array}$} & \multirow[b]{2}{*}{$\begin{array}{l}n \text { in } \\
\text { each } \\
\text { group }\end{array}$} & \multicolumn{2}{|c|}{ Group A (Black Hair) } & \multicolumn{2}{|c|}{ Group B (Brown Hair) } \\
\hline & & $\begin{array}{l}\text { Hair } \\
\text { Drug } \\
\text { Content }\end{array}$ & $\begin{array}{l}\text { \% of } \\
\text { Group }\end{array}$ & $\begin{array}{c}\text { Dair } \\
\text { Brug } \\
\text { Content }\end{array}$ & $\begin{array}{l}\% \text { of } \\
\text { Group }\end{array}$ \\
\hline 1 & 19 & 5 & 19 & 1 & 19 \\
\hline 2 & 17 & 10 & 17 & 2 & 17 \\
\hline 3 & 15 & 15 & 15 & 3 & 15 \\
\hline 4 & 13 & 20 & 13 & 4 & 13 \\
\hline 5 & 11 & 25 & 11 & 5 & 11 \\
\hline 6 & 9 & 30 & 9 & 6 & 9 \\
\hline 7 & 7 & 35 & 7 & 7 & 7 \\
\hline 8 & 5 & 40 & 5 & 8 & 5 \\
\hline 9 & 3 & 45 & 3 & 9 & 3 \\
\hline 10 & 1 & 50 & 1 & 10 & 1 \\
\hline
\end{tabular}

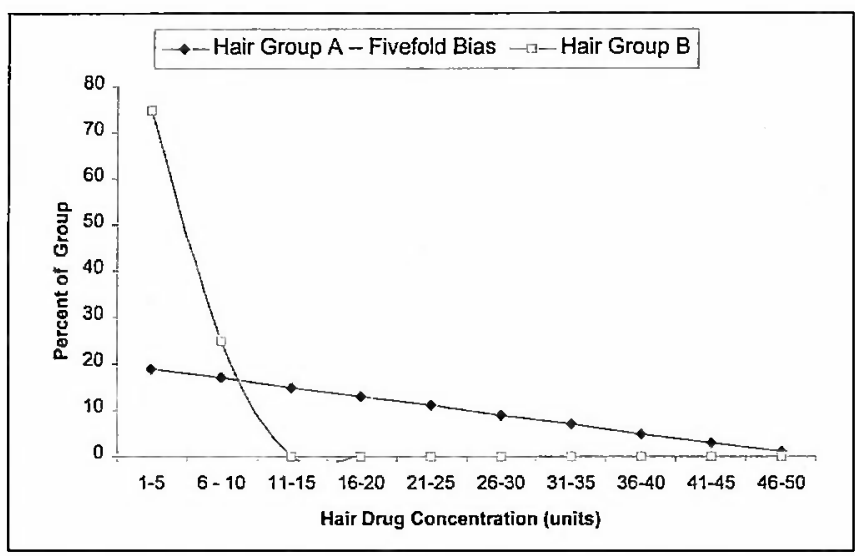

Figure 3 : Distribution of Hair Drug Concentrations for Two Hypothetical Populations with Non-Uniform Distribution of Doses over the Range of Dose and One Group Retaining Five Times more Drug Per Unit Dose.

In contrast to Figures 2 or 3 , which show a twofold or fivefold bias, if Group A had no bias, the distributions would be identical, as shown in Figure 4 .

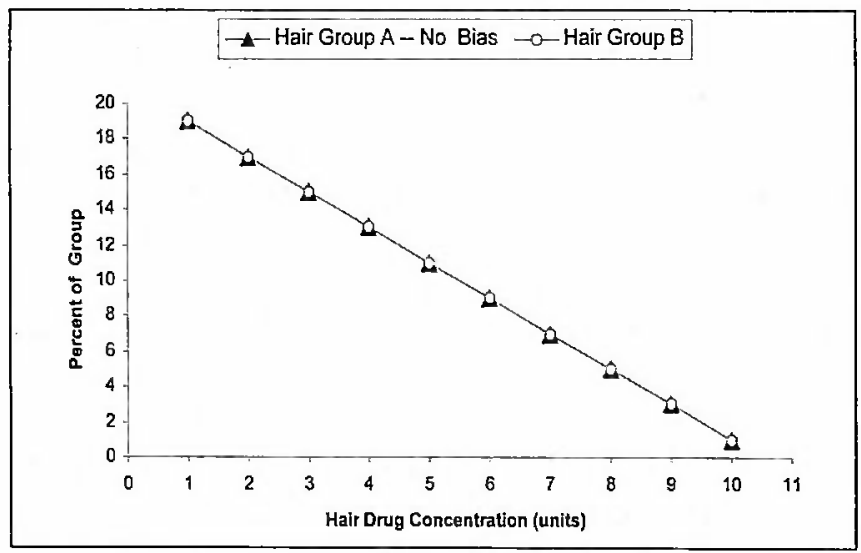

Figure 4 : Distribution of Hair Drug Concentrations for Two Hypothetical Populations with Non-Uniform Distribution of Doses over the Range of Doses and Both Groups Retaining the Same Amount of Drug Per Unit Dose.
In this way, studying the distributions of hair drug content, as described in the examples above, in populations of hair drug results can indicate whether or not there is a color bias, even when the drug doses are not known. Another way of evaluating these large sets of data is to calculate the mean concentrations of drug by decile (i.e., in tenths of the populations: the bottom $10 \%$ of results, the next $10 \%$, etc.). While mean concentrations of drugs in hair have been determined for entire populations of all drug users over the range from the cutoff to the highest values obtained $(31,36)$, this is not very helpful, since the range of results is very large with equally large variances. Dividing the populations into equivalent groups by decile allows comparison of groups that might be assumed to be more similar to each other in use patterns. For example, very light drug use is likely similar in nature whether it is by someone with black or with brown hair, and both groups would tend to fall below and around the cutoff in hair analysis. But if one group of subjects tends to retain more drug per unit dose, then this should reveal itself in these very low users as higher drug concentrations in the low deciles for the group that retains more drug per unit dose. For real samples, presented in the Results section, the analysis requires including all samples at very low concentrations, as close to zero as possible, which we do by including all samples down to LOD for each drug. This approach also benefits from very large sample size, so that each decile also contains a large $n$. For the same conditions described for Figure 2 above (more frequent low use than high use and a twofold bias), comparison of drug concentrations in hair for equivalent deciles of two populations would be that shown in Table IV and Figure 5. Note that the drug concentrations in the deciles of the population for Group A (Black) are twice that of the other group.

Table IV : Comparison of Hair Drug Content by Decile in Two Populations With Non-Uniform Distribution of Doses and One Group Retaining Twice the Drug Per Unit Dose.

\begin{tabular}{|c|c|c|}
\hline Decile & \multicolumn{2}{|c|}{ Average Hair Drug Content (units) } \\
\hline & Group A Black Hair) & Group B (Brown Hair) \\
\hline 1 & 2.0 & 1.0 \\
\hline 2 & 2.2 & 1.1 \\
\hline 3 & 4.0 & 2.0 \\
\hline 4 & 4.8 & 2.4 \\
\hline 5 & 6.0 & 3.0 \\
\hline 6 & 7.8 & 3.9 \\
\hline 7 & 9.2 & 4.6 \\
\hline 8 & 11.0 & 5.5 \\
\hline 9 & 13.2 & 6.6 \\
\hline 10 & 16.8 & 8.4 \\
\hline
\end{tabular}




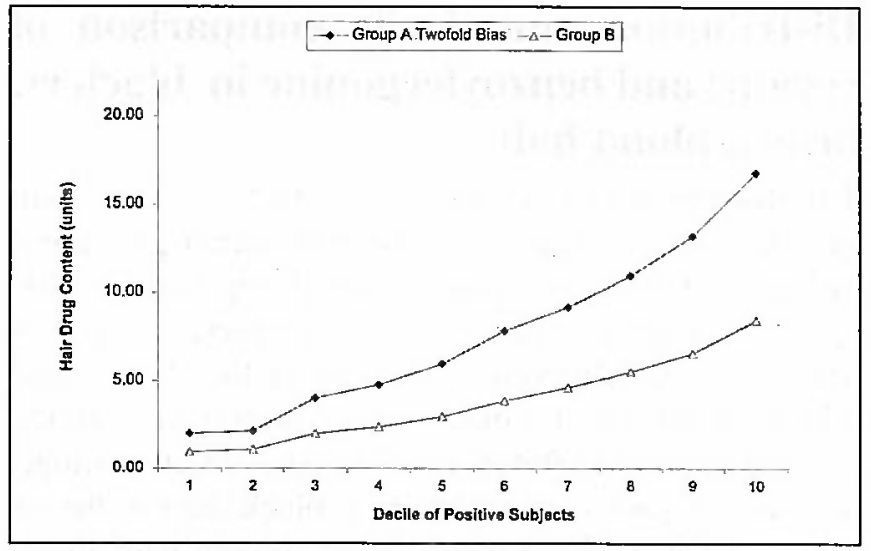

Figure 5 : Comparison of Hair Drug Content by Decile in Two Populations with Non-Uniform Distribution of Doses and One Group Retaining Two Times More Drug Per Unit Dose.

For a fivefold bias, again with a user population as described for Figure 2, the differences in the deciles are, of course, much larger, as shown in Table V and Figure 6.

Table V : Comparison of Hair Drug Content by Decile in Two Populations With Non-Uniform Distribution of Doses and One Group Retaining Five Times More Drug Per Unit Dose.

\begin{tabular}{|c|c|c|}
\hline \multirow{2}{*}{ Becile } & \multicolumn{2}{|c|}{ Average Hair Drug Content (units) } \\
\cline { 2 - 3 } & Group A (Black Hair) & Group B (Brown Hair) \\
\hline 1 & 5.0 & 1.0 \\
\hline 2 & 5.5 & 1.1 \\
\hline 3 & 10.0 & 2.0 \\
\hline 4 & 12.0 & 2.4 \\
\hline 5 & 15.0 & 3.0 \\
\hline 6 & 19.5 & 3.9 \\
\hline 7 & 23.0 & 4.6 \\
\hline 8 & 27.5 & 5.5 \\
\hline 9 & 32.5 & 6.6 \\
\hline 10 & 42.0 & 8.4 \\
\hline
\end{tabular}

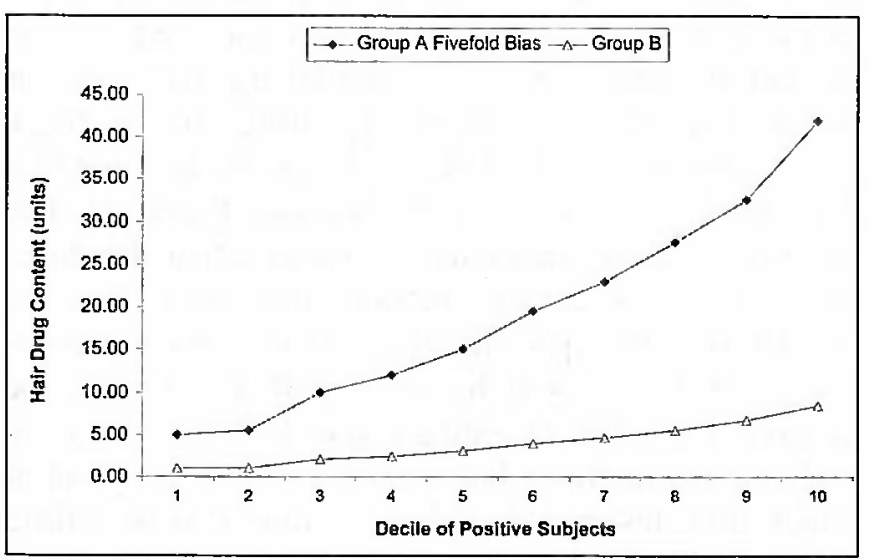

Figure 6 : Comparison of Hair Drug Content by Decile in Two Populations with Non-Uniform Distribution of Doses and One Group Retaining Five Times More Drug Per Unit Dose.
The above models serve as guides in recognizing a bias in actual workplace results. Even a twofold bias is clearly demonstrated by these methods, by both the distribution method in Figure 2 and the decile comparison of Figure 5. Some authors have postulated a bias as large as twentyfold for some drugs (26). These models predict that a fivefold bias would show truly extreme differences by both evaluations. Short of the impossible ideal of injected dose studies with large numbers of subjects, these analyses, while forced by the absence of dose information, are perhaps the most convincing way of appraising the possible existence of a color bias, due to the following features: very large sample size, use of actual human head hair data, no dependence on subjective and inaccurate drug-use histories, the ability to view the entire range of results for consistent trends rather than isolated averages of small or disparate sets of subjects.

\section{Results}

\section{Distribution and decile comparison of car- boxy-THC in black $v s$. brown/blond hair}

The distribution of carboxy-THC values in hair samples ranging from $0.2 \mathrm{pg} / 10 \mathrm{mg}$ hair to greater than $50 \mathrm{pg} / 10 \mathrm{mg}$ hair is shown in Figure 7. There is no evidence in the distribution that the black hair has any bias relative to the brown/blond group. The black hair containing 0.2 to $0.5 \mathrm{pg} / 10 \mathrm{mg}$ hair carboxy-THC represents a somewhat larger percentage of all results compared to the brown group, but there is no continuing trend of that nature, as seen in the range 0.6-1.9 $\mathrm{pg} / 10 \mathrm{mg}$ hair, where the percentage is lower, then at 2.0 - 2.9 the percentage is about the same, then again the percentage is lower at $3-3.9$, and higher again from 4 to 6.9 , and so on. This lack of bias over the entire range of drug content is consistent with the expectation that acidic drugs do not show a color bias because they do not bind to melanin, which is in higher concentrations in black hair than in brown hair (26).

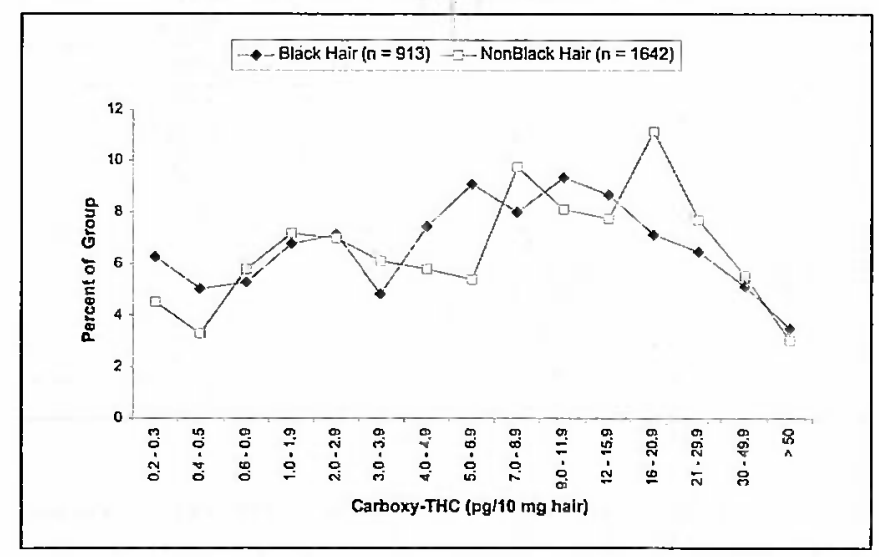

Figure 7 : Distribution of Hair Drug Concentrations of Carboxy-THC from LOD to the Limit of Linearity in Washed Black and Non-Black Workplace Testing Hair Samples. 
The lack of bias in carboxy-THC levels in hair is further corroborated by comparison of drug concentrations by decile of the positive population (Figure 8). 'There appears to be a slightly lower carboxy-THC concentration in the black samples in this comparison of deciles, although it is very small, with the standard deviations (SD's) overlapping in all deciles. In comparison with the model of what a bias would look like (Figure 5, twofold bias), the real-life results depicted in Figure 8 do not show any bias for either group with regard to carboxy-THC.

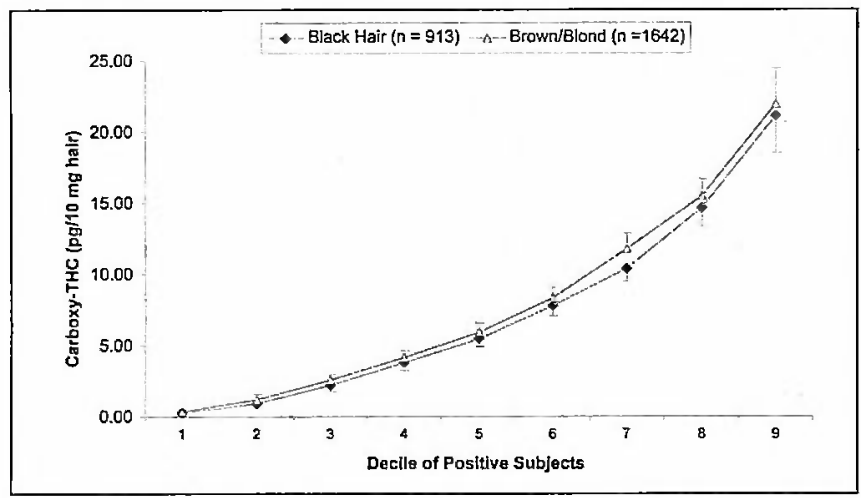

Figure 8 : Comparison by Decile of Hair Carboxy-THC Content in Black and Non-Black Workplace Testing Populations. Error marks indicate I S.D. of the mean value for the given decile.

To investigate further the possible existence of a melanin or color bias effect in carboxy-THC deposition in hair, 13 gray, or "salt and pepper" hair samples positive for carboxy-THC were selected. The white strands were separated from the black strands, and the white and black portions analyzed separately by GC/MS/MS. The results, shown in Table VI, show no difference in Carboxy-THC concentrations in the melanin-free (white) hair as compared with the black (high melanin content) hair.

Table VI : Carboxy-THC (pg/10 mg hair) in Salt \& Pepper Hair (grey hair).

\begin{tabular}{|c|c|c|}
\hline Sample\# & SALT (white) & PEPPER (black) \\
\hline 1 & 7.46 & 6.48 \\
\hline 2 & 43.84 & 47.13 \\
\hline 3 & 29.36 & 28.19 \\
\hline 4 & 20.18 & 19.05 \\
\hline 5 & 4.89 & 5.09 \\
\hline 6 & 29.59 & 26.86 \\
\hline 7 & 7.3 & 8.32 \\
\hline 8 & 20.1 & 24.75 \\
\hline 9 & 3.3 & 3.14 \\
\hline 10 & 10.09 & 7.23 \\
\hline 11 & 8.64 & 8.41 \\
\hline 12 & 2.17 & 2,08 \\
\hline 13 & 1.28 & 1.25 \\
\hline
\end{tabular}

Pairs are not significantly different by paired-sample t-test.

' In Figures 8, 10 and 12, the $10^{\text {th }}$ decile is not shown because samples above the limit of linearity $(50 \mathrm{pg} / 10 \mathrm{mg}$ hair for carboxy$\mathrm{THC}$, and $200 \mathrm{ng} / 10 \mathrm{mg}$ hair for cocaine and benzoylecgonine) are not always diluted, and therefore this decile, which includes such results, did not provide accurate quantitative mean values.

\section{Distribution and decile comparison of cocaine and benzoylecgonine in black vs. brown/blond hair}

The distribution of cocaine values in 5352 black hair samples and 3600 brown/blond hair samples is shown in Figure 9. Ranging from $0.2 \mathrm{ng} / 10 \mathrm{mg}$ hair to $\geq 200$ $\mathrm{ng} / 10 \mathrm{mg}$ hair, the values show a complete absence of any consistent difference or shift in the distribution which would reveal a bias of one group relative to the other. Any small difference in one concentration range, such as a higher concentration in black than in brown hair, is balanced by a reversal, i.e., brown hair higher than black, at another concentration.

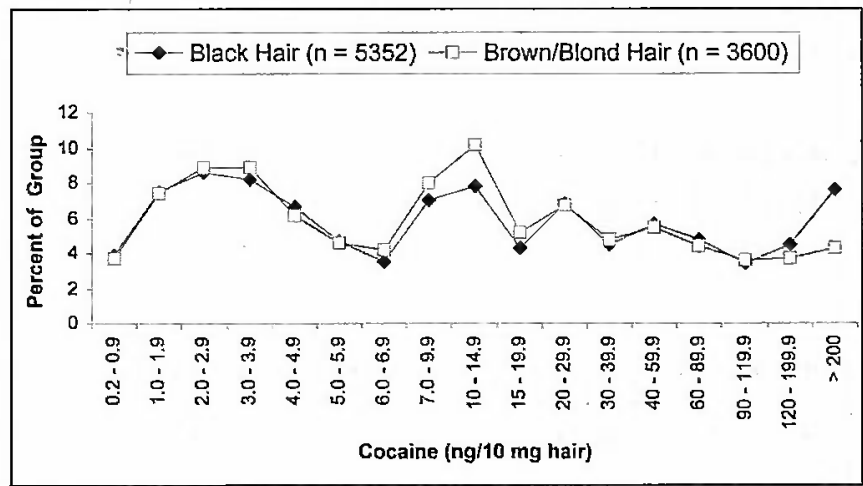

Figure 9 : Distribution of Hair Drug Concentrations of Cocaine from $L O D$ to the Limit of Linearity in Washed Black and Non-Black Workplace Testing Hair Samples.

Comparing the concentrations of cocaine in each decile of the black and brown/blond populations, as shown in Figure 10, we see identical amounts of drug in the two hair colors in the $1^{\text {st }}$ through $6^{\text {th }}$ deciles. These deciles cover the low concentration range of interest (from $0.2-\sim 12 \mathrm{ng} / 10 \mathrm{mg}$ hair) with the cutoff at 5 $\mathrm{ng} / 10 \mathrm{mg}$ hair. Since there is no difference between black and brown/blond hair drug concentrations for over half the population, and this half ranges from below to well past the cutoff, it is clear there is not a color bias for cocaine at the cutoff. In the top 3 deciles, as the hair drug concentrations increase well beyond the cutoff (approximately $20 \mathrm{ng} / 10 \mathrm{mg}$ hair), higher mean concentrations begin appearing in the black group but the concentrations observed are far from that expected from even a twofold bias (see Figure 5). The large SD's shown in Figure 10 suggest that the differences are not meaningful in this context but instead are consistent with expected variations in biological measures. Also, as noted by other authors $(39,40)$, the concern in workplace testing is not about differences at higher concentrations but at the cutoff, or the point at which drug testing determines a subject to be a drug user. In this decile comparison, the lack of a constant ratio of one group to the other across the population indicates there is no consistent color bias in hair analysis for cocaine. 


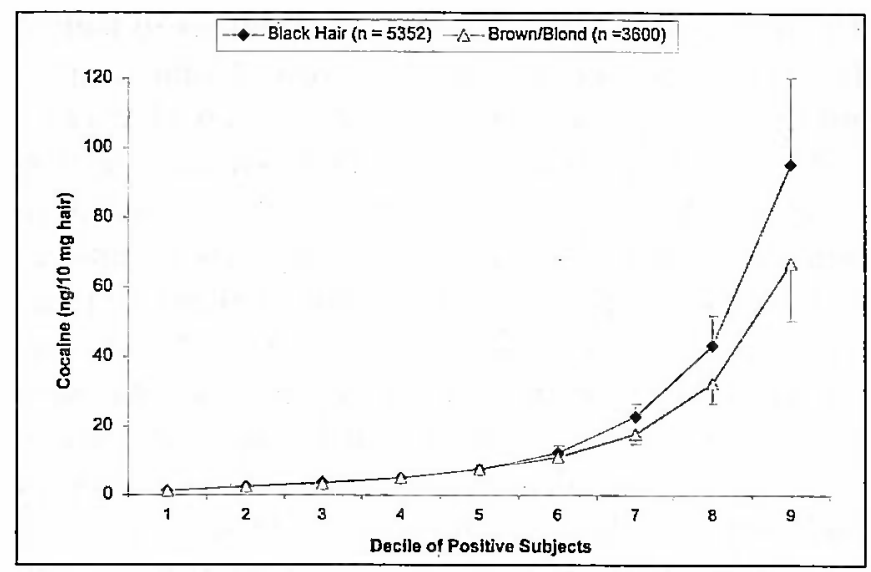

Figure 10: Comparison by Decile of Hair Cocaine Content in Washed Black and Non-Black Workplace Testing Populations. Error marks indicate 1 S.D. of the mean value for the given decile.

Figure 11 shows the distribution of benzoylecgonine values in 4287 black hair samples and 3185 brown/blond hair samples. As is the case for cocaine, there is no consistent difference in the distributions of hair drug concentrations between the two groups-the percent of samples at each concentration is generally the same for both. At the level of 0.2-0.4 ng/10 mg hair, there are fewer brown/blond samples than black, but then the two groups are the same at $0.5-0.9 \mathrm{ng} / 10 \mathrm{mg}$ hair, and more brown/blond than black at $1.0-1.9$ $\mathrm{ng} / 10 \mathrm{mg}$ hair; from there on, the percent of samples at each concentration is essentially similar for both groups continuing to the highest concentrations of 199.9. ${ }^{2}$

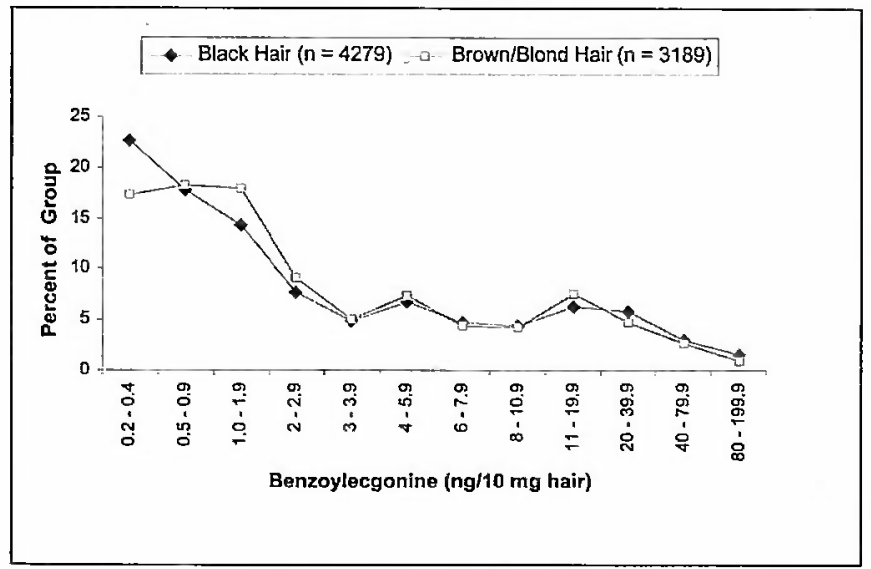

\section{Figure 11}

When the benzoylecgonine population is broken into deciles and these compared, as shown in Figure 12, the brown/blond hair means are essentially identical to those of the black hair group. The small separation of means for the two groups in the $8^{\text {th }}$ and $9^{\text {th }}$ deciles is

\footnotetext{
2 Six black hair samples and 14 brown hair samples above 200 $\mathrm{ng} / 10 \mathrm{mg}$ hair are not included in the chart.
}

meaningless in light of the large SD's. The lack of a bias for benzoylecgonine, as for carboxy-THC, is not unexpected even for proponents of melanin bias theories, as it is consistent with the belief that lack of basicity of an analyte is associated with lack of hair color bias (40).

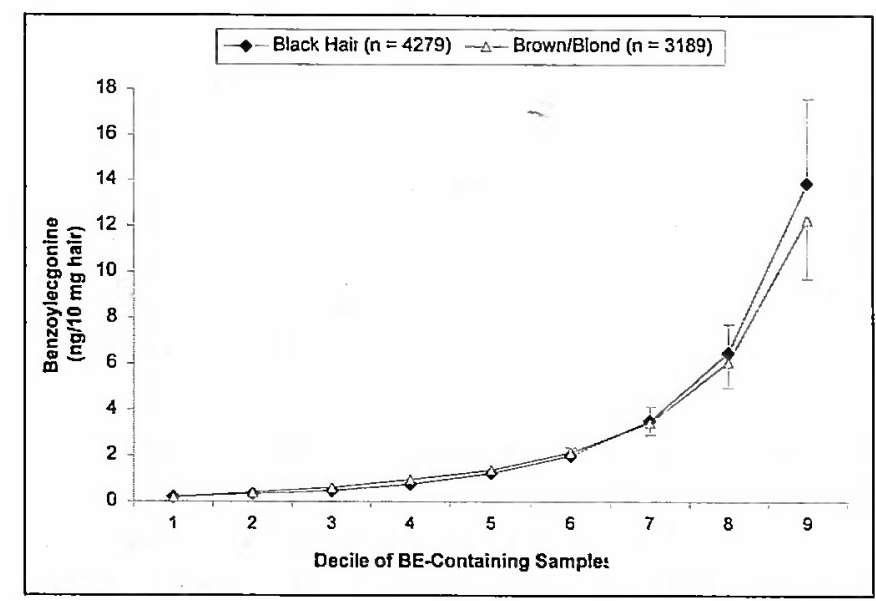

Figure 12 : Comparison by Decile of Hair Benzoylecgonine Content in Washed Black and Non-Black Workplace Testing Hair Samples. Error marks indicate 1 S.D. of the mean value for the given decile.

\section{Distribution and decile comparison of morphine and 6-MAM in hair}

The presence of a possible color bias in morphine determinations in hair was evaluated with a sample of 285 black hair samples and 272 brown and blond hair samples, with concentrations from $0.5-93.8 \mathrm{ng} / 10 \mathrm{mg}$ hair for the black hair and $0.5-125 \mathrm{ng} / 10 \mathrm{mg}$ hair for the brown and blond hair group. In the distribution of values shown in Figure 13, there is no consistent trend in the distribution of the population to indicate a bias of either group relative to the other. If there were a bias toward higher hair values for black hair, the points for brown/blond hair at the left of the chart would need to be higher than those of the black group, as described in Figure 2. Instead, the black percentages are slightly higher than the brown/blond, up to $1.4 \mathrm{ng} / 10 \mathrm{mg}$ hair. At $1.5-1.9 \mathrm{ng} / 10 \mathrm{mg}$ hair, the two groups are identical; then the black group is higher again at $2-2.4 \mathrm{ng} / 10 \mathrm{mg}$ hair, reversing to the brown/blond group being higher from $2.5-6.9$, with another reversal to black greater than brown/blond at $7-8.9 \mathrm{ng} / 10 \mathrm{mg}$ hair, with such continuing reversals in the comparisons up to the highest concentrations. Without a consistent trend of any kind, there is no evidence of a systematic color bias in these morphine hair results. With the variations seen in these data, however, one can understand how studies with small numbers of samples might mistakenly conclude that a bias might exist. 


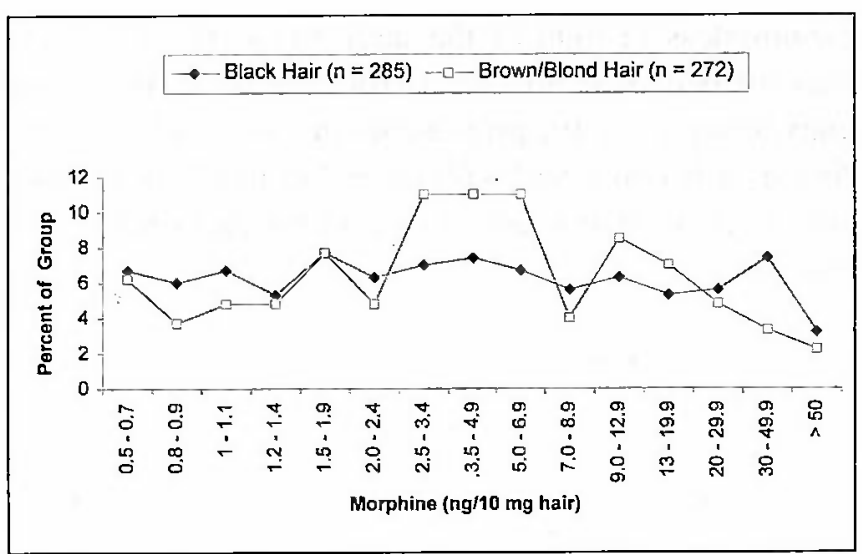

Figure 13 : Distribution of Hair Drug Concentrations of Morphine from $L O D$ to the Limit of Linearity in Washed Black and Non-Black Workplace Testing Hair Samples.

The lack of a bias is confirmed by the hair morphine concentrations by decile of the population shown in Figure 14. The concentrations of morphine in the lower 6 deciles appear to be very slightly larger in the brown/blond hair group than in the black hair, contrary to the expected result if there were a color bias due to melanin content. The concentrations in these deciles are from 0.5 to approximately $4 \mathrm{ng} / 10 \mathrm{mg}$ hair, or twice the cutoff concentration. This situation reverses to show slightly higher concentrations in the black hair at the $7^{\text {th }}$ decile and increasing toward higher concentrations in the $8^{\text {th }}$ to $10^{\text {th }}$ deciles, with the SD's at the higher concentrations becoming increasingly large also. In this decile comparison, the lack of a constant ratio of one group relative to the other across the entire population is further evidence that there is no consistent color bias in hair analysis results for morphine.

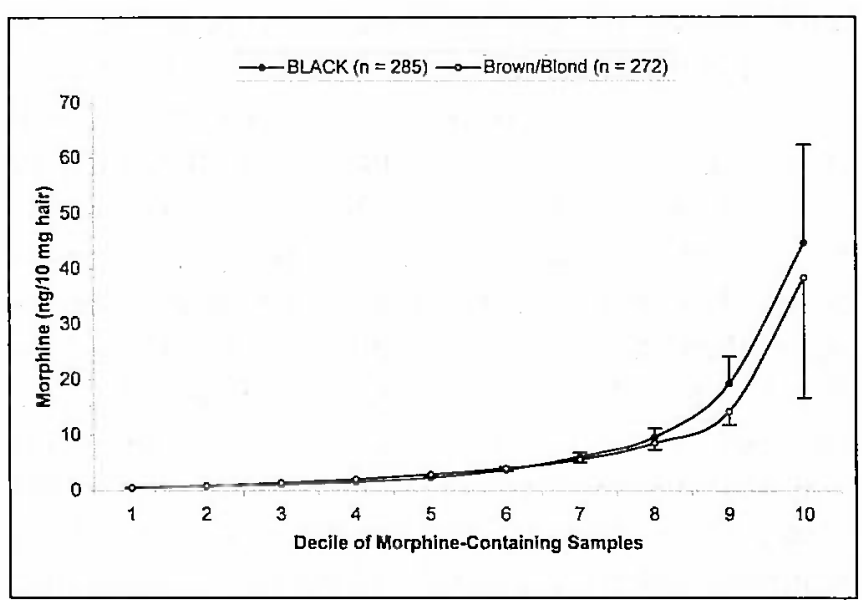

Figure 14 : Comparison by Decile of Hair Morphine Content in Washed Black and Non-Black Workplace Testing Hair Samples. Error marks indicate 1 S.D. of the mean value for the given decile.
The distributions of 6-MAM concentrations in hair of 165 black hair samples and 117 brown/blond samples are shown in Figure 15. Concentrations of 6-MAM ranged from $0.5 \mathrm{ng} / 10 \mathrm{mg}$ hair (LOD) to greater than 100 $\mathrm{ng} / 10 \mathrm{mg}$ hair. The distributions of these concentrations are essentially the same in the two groups, as there is no suggestion that the brown/blond hair has more results in the lower ranges of values. This is corroborated by examining the mean values of equivalent decile groups in Figure 16, where the means of the two groups are so identical that they are exactly on top of each other, all the way up to the $7^{\text {th }}$ decile. The small differences between means at these higher deciles fail to indicate a bias in the absence of any trend below these levels, and are likely meanigless in light of the overlap of the SD's.

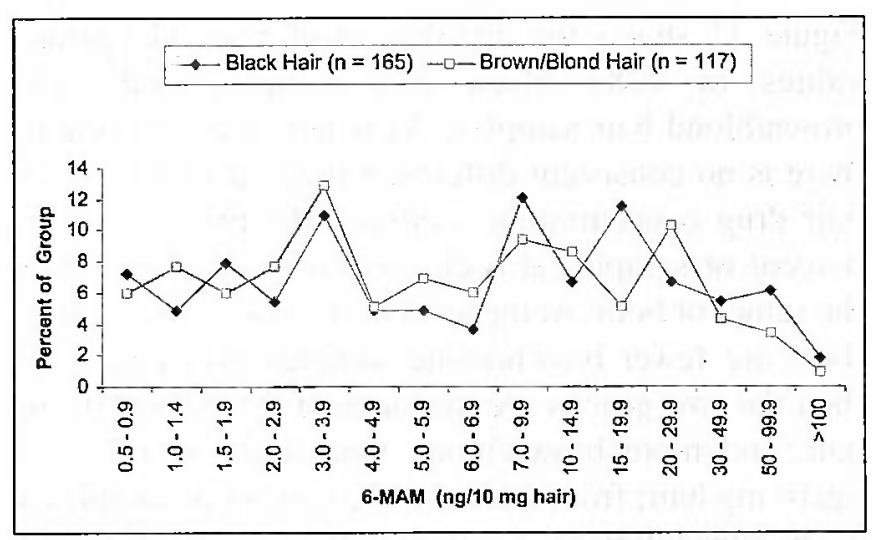

Figure 15 : Distribution of Hair Drug Concentrations of 6MAM from LOD to the Limit of Linearity in Washed Black and Non-Black Workplace Testing Hair Samples.

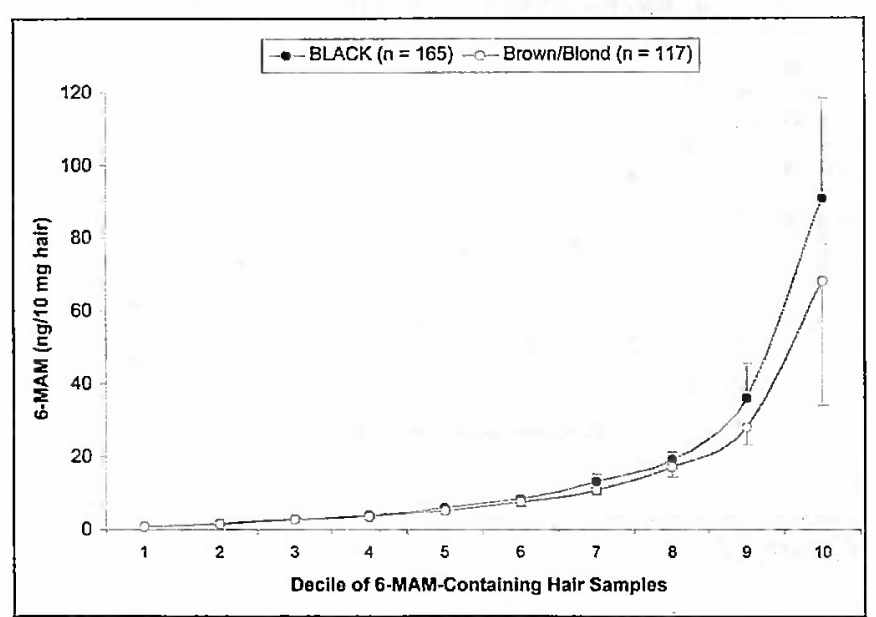

Figure 16: Comparison by Decile of Hair 6-MAM Content in Washed Black and Non-Black Workplace Testing Hair Samples. Error marks indicate I S.D. of the mean value for the given decile. 
It is especially interesting to examine hair codeine results, because codeine has been utilized as a model drug for opiates, and the results used as "proof" that there is a color bias in hair not just for codeine results, as measured by the methods of these investigators (17), but also by inference for other opiates such as morphine. As demonstrated above, the extrapolation of the presumed color bias in codeine results to morphine does not hold. An investigation of whether a color bias for codeine can be demonstrated in a large population follows.

The distribution of codeine results of 744 black hair samples and 431 brown/blond samples was evaluated and is depicted Figure 17. At first there is a suggestion of the brown/blond hair falling in higher numbers in the low concentration range, but above $2.4 \mathrm{ng} / 10 \mathrm{mg}$ hair there is no consistent pattern once again, as the comparisons reverse themselves across the population, finally ending up with the brown/blond hair having more samples with the highest concentrations. The model for bias requires not only that one region of the distribution shows differences, but that there be a high percent of low results for the brown/blond hair and a lower percent of high results. (See, for example, the distributions in Figures 2 and 3, which depict hypothetical groups retaining more drug than the other group.) This is clearly not the case for these codeine results as the percentages of samples in the two groups, moving toward higher concentrations, reverse repeatedly relative to one another. As described in the Methods section, this population of codeine positives includes only codeinepositive samples selected for confirmation by virtue of concurrent presence of morphine detected in the RIA screening assay. Whether this means of selecting codeine-positive samples might have a bearing on the distribution of positive results is unlikely, but might merit investigation.

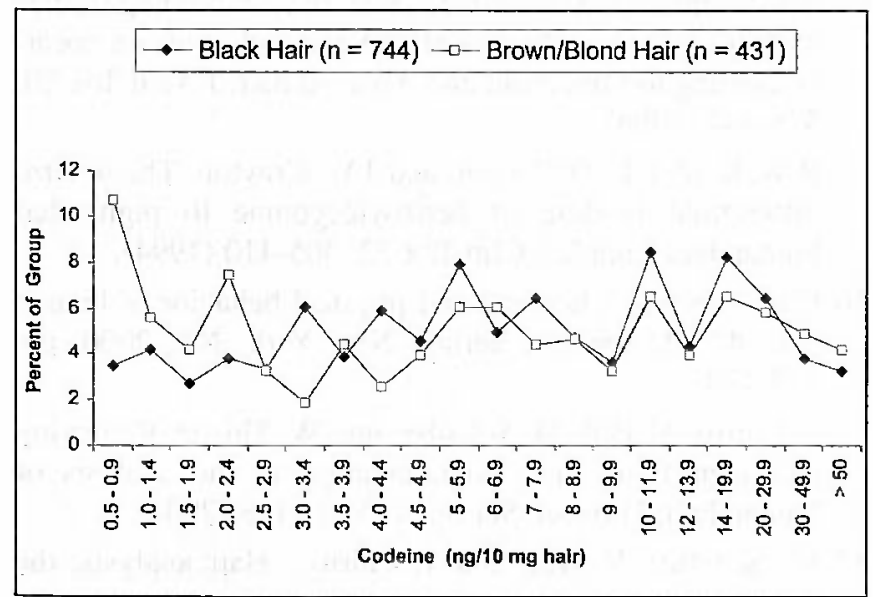

Figure 17 : Distribution of Hair Drug Concentrations of Codeine from LOD to the Limit of Linearity in Washed Black and Non-Black Workplace Testing Hair Samples.
The lack of a bias for codeine in the distribution of the results is corroborated by inspecting the hair concentrations of the two groups by decile (see Figure 18). A bias as great as 15 -fold has been proposed for codeine (26); referring to figures 5 (twofold bias model) and 6 (fivefold bias model), such a large effect would be clearly demonstrated in this large sample of results. Instead, there is barely a suggestion that the black group is slightly more concentrated in the lower deciles, with this trend vanishing at the high deciles where the concentrations of codeine actually appear higher in the brown/blond hair group. The small separation of means for the two groups in the $9^{\text {th }}$ decile is insignificant given the large SD's. Also, these results indicate that if there is a melanin or color bias for codeine in some laboratories, it may be an artifact of the particular methodologies of those laboratories, as it is certainly not present in results produced by the methods in this laboratory.

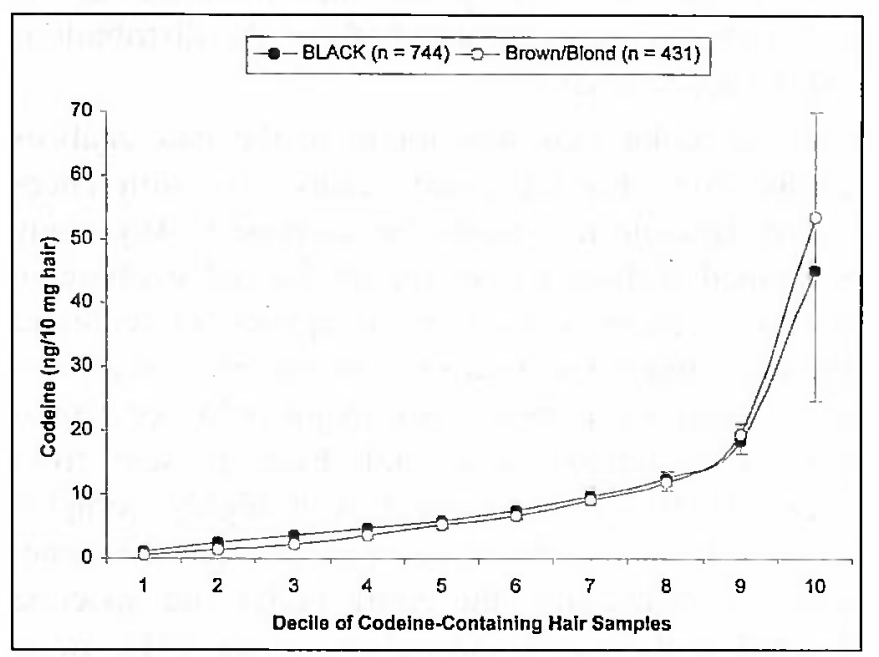

Figure 18 : Comparison by Decile of Hair Codeine Content in Washed Black and Non-Black Workplace Testing Hair Samples. Error marks indicate 1 S.D. of the mean value for the given decile.

\section{Conclusions}

The results presented represent extremely large sample sizes of head hair samples analyzed for drugs of abuse: cocaine, benzoylecgonine, morphine, 6-MAM, codeine, and carboxy-THC. A full range of hair drug values (from the lowest detectible values to highest values or limits of linearity) have been utilized to study results under conditions of very light use to increasing use that results in positive hair results-that is, to include all users of drugs rather than only those that are positive by a cutoff that some have suggested may be discriminatory (40). An attempt was made with these data to rigorously evaluate whether there is a pattern of hair color bias in the results obtained with the methods of 
our laboratory, and, by extension, to consider whether hair color bias is method dependent. While the demonstrated lack of bias in carboxy-THC and benzoylecgonine results is consistent with predictions that neutral and acidic drugs do not bind to melanin, these results also show a similar absence of bias for cocaine, morphine, -MAM, and codeine.

It is not likely that the absence of hair color effects in our analyses were due to selection of samples by a screening procedure already eliminating the low-drugbinding samples. First, the screening assay is performed on unwashed samples, and also the antibodies react with parent drug and metabolites, with the result that many more samples, especially near the cutoff, are positive in the screening assay than in the confirmation analyses. The stronger consideration, however, is that if a pre-selection of samples had occurred so as to camouflage the bias at the lower hair drug concentrations, the effect of such a shift of the populations relative to each other would be to exaggerate the differences at the higher drug concentrations, both in the distributions and the decile analyses.

Since no color bias was found in the hair analysis results from this laboratory, causes for differences among laboratories should be addressed. Any study performed without aggressive, prolonged washing of the hair samples cannot be interpreted to represent ingestion, much less to assess the presence of a color effect. Washing addresses two major influences: environmental contamination and drugs present from sweat. In this regard, sweat is a highly complex variable. Formed by two types of glands, eccrine (generally distributed over the entire body) and apocrine (located in the axilla and pubic regions) (41), sweat production varies greatly among individuals, depending on gender, exertion, stress, climate and season, hormonal status, clothing, nutritional and hydration states, and many other factors. Compounding the variations in sweat production, the kinds and frequencies of shampoo and conditioner treatments used with different hairstyles also affect the amount of sweat residues left on hairs. In addition, the effects of an individual's sweat exposure on his/her own hair can vary greatly for different hair types. For example, porous hair may easily soak up hundreds of times more drug than a nonporous hair. Such drug needs to be removed by effective, extended washing procedures $(12,13)$. With these considerations, studies that purport to show hair color effects, but use inadequate or invalid decontamination and/ or extraction methodologies must be weighted accordingly. In the present paper, analyses of large numbers of results obtained with extensively washed hair dissolved by enzymatic digestion followed by extraction of the melanin-free component, show no evidence of color bias for cocaine, benzoylecgonine, morphine, 6-MAM, codeine, and carboxy-THC.

\section{Acknowledgment}

The authors wish to thank Cameron Hill, of the Graduate Department of Mathematics, University of California at Berkeley, for his thoughtful contributions to this manuscript.

\section{References}

1. L. Potsch, G. Skopp, and G. Rippin. A comparison of ${ }^{3} \mathrm{H}-$ cocaine binding on melanin granules and human hair in vitro. Int J Leg. Med. 110: 55-62 (1997).

2. H.J. Broxterman, J.S.G. Smit, J. Van der Plas, A.VanLangevelde, R.D.M. Belfroid, G.T.H. Van Kempen, and J.A. Van der Krogt, Binding of $\left.{ }^{3} \mathrm{H}\right]$ flunitrazepam and $[3 \mathrm{H}]$ piperone to melanoma cell membrane preparations. Cancer Letters 28: 177-186 (1985).

3. C. R.Borges, J. C. Roberts, D. G.Wilkins, and D. Rollins. Cocaine, benzoylecgonine, amphetamine, and $\mathrm{N}$-acetylamphetamine binding to melanin subtypes. J Anal Tox 27: 125-134 (2003).

4. D.J. Claffey, P.R. Stout, and J.R. Ruth. ${ }^{3} \mathrm{H}-$ nicotine, ${ }^{3} \mathrm{H}$-flunitrazepam, and ${ }^{3} \mathrm{H}$-cocaine incorporation into melanin: A model for the examination of drug-melanin interactions. J Anal Tox 25: 607-611 (2001).

5. R.E. Joseph, Jr., W.J. Tsai, L.I. Tsao, T.P. Su., and E.J. Cone, In vitro characterization of cocaine binding sites in human hair, J Pharm Exp Ther 282: 1228-1241 (1997).

6. D.A. Kidwell, E.H.Lee, and S.F DeLauder. Evidence for bias in hair testing and procedures to correct bias, Forensic Sci Int 107: 39-61 (2000).

7. P.R.Stout, and J.A. Ruth, Comparison of in vivo and in vitro deposition of rhodamine and fluorescein in hair. Drug Met and Dep 26: 943-948 (1998).

8. R.E.Joseph, T.P. Su, and E.J. Cone. In vitro binding studies of drugs to hair: influence of melanin and lipids on cocaine binding to Caucasoid and Africoid hair, J Anal Tox 20: 338-344 (1996).

9. R.W. Reid, F.L. O'Connor, and J.W. Crayton. The in vitro differential binding of benzoylecgonine to pigmented human hair samples, Clin Tox 32: $405-410$ (1994).

10. C.R. Robbins. Chemical and physical behavior of human hair. $4^{\text {th }}$ ed. Springer-Verlag, New York, NY, 2000, pp. 178-179.

11. T. Cairns, V. Hill, M. Schaffer, and W. Thistle. Removing and identifying drug contamination in the analysis of human hair. Forensic Sci Int 145: 97-108 (2004).

12. M. Schaffer, V. Hill, and T. Cairns. Hair analysis: the requirement for effective wash procedures and Effects of concentration and porosity in contamination and decontamination. J. Anal. Tox. 29: 319-326 (2005). 
13. P.R.Stout. and J.A. Ruth, Deposition of $\left[{ }^{3} \mathrm{H}\right]$ cocaine, $\left[{ }^{3} \mathrm{H}\right]$ nicotine and $\left[{ }^{3} \mathrm{H}\right]$ flunitrazepam in mouse hair melanosomes after system administration. Drug Metab and Disposition 27: 731-735 (1999).

14. L.Potsch, G. Skopp, and M.R. Moeller. Influence of pigmentation on the codeine content of hair fibers in guinea pigs, J Forensic Sci 42: 1095-1098 (1997).

15. M.H.Slawson, D.G.Wilkins, R.L Foltz and D.E. Rollins. Quantitative determination of phencyclidine in pigmented and nonpigmented hair by ion-trap mass spectrometry, J. Anal Tox 20: 350-354 (1996).

16. S.P.Gygi, R.E. Joseph, Jr., E.J. Cone, D.G, Wilkins, and D.E. Rollins. Incorporation of codeine and metabolites into hair, Drug Metab and Disposition 24: 495-501 (1996).

17. S.P Gygi., D.G. Wilkins, and D.E. Rollins. A comparison of phenobarbital and codeine incorporation into pigmented and nonpigmented rat hair, J. Pharm Sci 86: 209-213 (1997).

18. D.L. Hubbard, D.G. Wilkins, and D.E. Rollins. The incorporation of cocaine and metabolites into hair: effects of dose and hair pigmentation, Drug Metab and Disposition 28: 1464-1469 (2000).

19. M.H. Slawson, D.G. Wilkins, and D.E. Rollins. The incorporation of drugs into hair: relationship of hair color and melanin concentration to phencyclidine incorporation, J. Anal Tox 22: 406-413 (1998).

20. S.J. Green, and J.F. Wilson. The effect of hair color on the incorporation of methadone into hair in the rat, J. Anal Tox, 20: 121-123 (1996).

21.C.R. Borges, D.G. Wilkins, and D.E. Rollins. Amphetamine and $\mathrm{N}$-acetylamphetamine incorporation into hair: an investigation of the potential role of drug basicity in hair color bias, J Anal Tox, 25: 221-227 (2001).

22. D.E. Rollins, S.P. Gygi, and D.G.Wilkins. Distribution of codeine into hair. in proceedings. of 1995 int. conference and workshop for hair analysis in forensic toxicology, R. deZeeuw, I. Al Hosani, S. Munthiri, and A. Maqbool, Eds. Abu Dhabi, 1995, pp 118-135.

23. J. Robertson. .Forensic and microscopic examination of human hair. In Forensic Examination of Hair. J. Robertson, Ed. Taylor and Francis, Philadelphia, PA, 1999, pp. 79-84.

24. S.P. Gygi, Wilkins, D.G., and Rollins, D.E. Distribution of codeine and morphine into rat hair after long-term daily dosing with codeine. J. Anal. Toxicol. 19: 387-391 (1995).

25. V. Hill, T. Cairns, C.Cheng, and M. Schaffer, Analysis of opiates in hair: clinical and workplace subjects, and codeine and poppy seed effects, J. Anal. Toxicol., October 2005, in press

26. R.S. Kronstrand, S. Forstberg-Peterson, B. Kagedal, J. Ahlner, and G. Larson, Codeine concentration in hair after oral administration is dependent on melanin content, Clin Chem 45: 1485-1494 (1999).

27. G.L Henderson, M.R. Harkey, and C. Zhou, Incorporation of isotopically labeled cocaine into human hair: Race as a factor, J Anal Tox 22: 156-165 (1998).

28. R.Kronstrand, M.C. Andersson, J. Ahlmer, and G. Larson, Incorporation of selegiline metabolites into hair after oral selegiline intake, J Anal Tox 25: 594-601 (2001).
29. R.Kronstrand, J. Ahlner, N. Disdar, and G. Larson, Quantitative analysis of desmethylselegiline, methamphetamine and amphetamine in hair and plasma from Parkinson patients on long-term selegiline medication, J Anal Tox 27: 135-141 (2003).

30.D.E.Rollins, D.G. Wilkins, G.C. Krueger, M.P. Augsburger, M. Atsuhiro, C. O'Neal, C.R. Borges, and M.H. Slawson, The effect of hair color on the incorporation of codeine into human hair, J Anal Tox 27: 545-551 (2003).

31. T. Mieczkowski and R. Newel. A statistical examination of hair color as a potential biasing factor in hair analysis. Forensic Sci Int 107: 13-18 (2000).

32. R.C.Kelly, T.Mieczkowski, S.A Sweeney, and J.A Bourland. Hair analysis for drugs of abuse: Hair color and race differentials or systematic differences in drug preferences? Forensic Sci Int.107: 63-86 (2000).

33. T. Mieczkowski, D. Barzelay, B. Gropper, and E. Wish. Concordance of three measures of cocaine use in an arrestee population: hair, urine and self-report. J. Psychoactive Drugs, 23: 241-249 (1991).

34. T. Mieczkowski and R. Newel. An evaluation of patterns of racial bias in hair assays for cocaine: black and white arrestees compared. Forensic Sci Int 63: 85-98 (1993).

35. B.H. Hoffman, Analysis of race effects on drug test results. J Occup and Environ Medicine 41: 612-614 (1999).

36. T. Mieczkowski. Assessing the potential of a "color effect" for hair analysis of 11-nor-9-carboxy- $\Delta 9$-tetrahydrocannabinol: analysis of a large sample of hair specimens. Life Sciences 74: 463-469 (2003).

37. T. Mieczkowski, K.M. Lersch, and M. Kruger. Police drug testing, hair analysis, and the issue of race bias. Criminal Justice Rev 27: 124-140 (2002).

38. T. Mieczkowski. Effect of color and curvature on the concentration of morphine in hair analysis. Forensic Sci Comm 3: 1-5 ( 2001).

39. D.A. Kidwell, E.H. Lee, and S.F. DeLauder. Evidence for bias in hair testing and procedures to correct bias. Forensic Sci Int 107: 39-61 (2000).

40.C.R. Borges, D.G. Wilkins, and D.E. Rollins. Amphetamines and $\mathrm{N}$-acetylamphetamine incorporation into hair: An investigation of the potential role of drug basicity in hair color bias. J. Anal Tox 25: 221-227 (2001).

41. F. Pragst, M. Rothe, K. Spiegel, and F. Spokert. Illegal and therapeutic drug concentration in hair segments. A timetable of drug exposure? Forensic Sci. Rev 10: 81-111 (1998).

42. W.A. Baumgartner, U.S. Patent No. 5,324,642, June 28, 1994.

43. U.S. Food and Drug Administration, Center for devices and radiological health

http://www.accessdata.fda.gov/scripts/cdrh/cfdocs/cfPMN /pmn.cfm/

44. W. A. Baumgartner, and V.A. Hill. Hair analysis for drugs of abuse: sample preparation techniques Forensic Sci. Int. 63: 121-135(1993).

45. T.Cairns, V. Hill, T. Schaffer, and W. Thistle, Levels of cocaine and its metabolites in washed hair of demonstrated cocaine users and workplace subjects. Forensic Sci. Int., 145: 175-181 (2004). 